\title{
Implementation of an 8K-DTV broadcast system
}

\section{using SDR}

\author{
Ricardo Seriacopi Rabaça \\ George Henrique Maranhão Garcia de Oliveira \\ Fadi Jerji \\ Cristiano Akamine
}

\section{CITE THIS ARTICLE}

Rabaça, Ricardo Seriacopi; de Oliveira, George Henrique Maranhão Garcia ; Jerji, Fadi; Akamine, Cristiano; 2019. Implementation of an 8K-DTV broadcast system using SDR. SET INTERNATIONAL JOURNAL OF BROADCAST ENGINEERING. ISSN Print: 2446-9246 ISSN Online: 2446-9432. doi: 10.18580/setijbe.2019.1. Web Link: http://dx.doi.org/10.18580/setijbe.2019.1 


\title{
Implementation of an 8K-DTV broadcast system using SDR
}

\author{
Ricardo Seriacopi Rabaça, George Henrique Maranhão Garcia de Oliveira, Fadi Jerji, and \\ Cristiano Akamine, Member, SET
}

\author{
Electrical Engineering and Computing Program \\ Mackenzie Presbyterian University \\ São Paulo, Brazil
}

ricardo_sr2@hotmail.com, george.oliveira@mackenzie.br, fadi.jerji@gmail.com, cristiano.akamine@mackenzie.br

\begin{abstract}
This paper presents an implementation of an 8KDTV transmitter and receiver in Software Defined Radio/GNU Radio Companion. The main idea of this work is to provide a modified digital TV broadcast system, based on the Brazilian system (ISDB-T ${ }_{B}$ ), using two adjacent channels of $6 \mathrm{MHz}$, channel bonding technique, soft-decision demapper, powerful channel coding and high order modulations, to achieve high bit rates and allow the transmission and reception of content in Ultra High Definition (8K) using indoor antennas. The implementation is done using the GNU Radio Companion software along with a Software Defined Radio platform to transmit and receive the Radio Frequency signal.
\end{abstract}

Keywords-Integrated Services Digital Broadcasting Terrestrial - Version B $\left(\right.$ ISDB-T $\left._{B}\right)$, Ultra High Definition Television (UHDTV), Channel Bonding (CB), Low-Density Parity-Check (LDPC), Software Defined Radio (SDR), GNU Radio Companion (GRC).

\section{INTRODUCTION}

Due to increasing demand for higher resolution from content consumers, broadcast systems need to support higher bit rates. To achieve these goals, it is necessary to change some of broadcast system's characteristics such as the maximum modulation order, video compression method, physical layer technique and even the bandwidth.

In Brazil, the commercial transmission of Integrated Services Digital Broadcasting Terrestrial - Version B (ISDB- $\mathrm{T}_{B}$ ) started in 2007 [1]. This system is based on the Japanese digital TV standard, but with some modifications in order to fit the Brazilian scenario [2]. Also, there is the fact that the Brazilian Analogue switch-off (ASO) process will be completed in 2023 [3]. Thus, it is necessary to develop a new standard or an evolution of the existent ISDB-T $_{B}$ standard that allows content transmission in Ultra High Definition (UHD), such as $4 \mathrm{~K}$ and $8 \mathrm{~K}$ resolutions.

In recent years, the consumer market has come to have a higher demand for UHD services, however, several papers

This work was supported in part by the Coordination for the Improvement of Higher Education Personnel (CAPES), National Council for Scientific and Technological Development (CNPq) and MackPesquisa. regarding the developments on using Ultra High Definition Television (UHDTV) signals where presented at the Japan Broadcasting Corporation (NHK) in 1995 [4]. In 2002, the first public demonstration of an $8 \mathrm{~K}$ signal transmission was done at the NHK science and technology research laboratory. In 2005, another public exhibition was held at Expo 2005 in Japanese province of Aichi. In 2006, the first $8 \mathrm{~K}$ demo was done at the National Association of Broadcasters (NAB) Show. In 2012, "Rec. 2020" or "BT.2020" was regulated by the International Telecommunication Union-Radio-communications Sector (ITU-R) and a demonstration was held at the Olympic games in London. In 2016, satellite transmission tests were performed, a presentation during the Olympic games at Rio de Janeiro was realized and $8 \mathrm{~K}$ compatible equipment was produced [4]-[6]. In 2017, an interface capable of transmitting $100 \mathrm{Gbps}$ and compatible with $8 \mathrm{k} / 50 \mathrm{p}-60 \mathrm{p} / 4: 4: 4 / 12$ bit or $8 \mathrm{k} / 100 \mathrm{p} 120 \mathrm{p} / 4: 2: 2 / 10 \mathrm{bit}$ image formats was developed. DC level balancing and clock signal recovery were done using 8 to 10 bit encoding [7].

The new standard developed by the Advanced Television Systems Committee (ATSC) the "ATSC 3.0", already in use in countries such as the United States and South Korea, allows the transmission of content in $4 \mathrm{~K}$ deploying several improvements such as modern modulation and multiplexing techniques and powerful coders [8]-[10].

To allow content transmission in $4 \mathrm{~K}$ and $8 \mathrm{~K}$, high bit rates are required. To achieve this goal, it becomes necessary to analyze new techniques that can be applied in an already existing system. The ISDB-T I $_{B}$ allows for bit rates up to 23.234 Mbps using a bandwidth of $6 \mathrm{MHz}$ and its highest modulation order (64-QAM) [11]. To reach the main objective of this work, which is the transmission of $8 \mathrm{~K}$ content, a bit rate between 70 and $100 \mathrm{Mbps}$ is required, depending on the used video configuration [12].

There are some studies such as [13]-[15], which demonstrate the use of modern modulation techniques, coding and multiplexing, so that it could reach a higher bit rates (to allow the transmission of $4 \mathrm{~K}$ content in the enhanced layer) and still allow transmission of the traditional ISDB- $\mathrm{T}_{B}$ in the core layer using the Layer Division Multiplexing (LDM) technique. The 
main advantages of this method are the efficient spectrum use and the increase in the amount of data transmitted [16].

In this work the main idea is different, since it is desired to achieve even higher bit rates, which allow the transmission of content in $8 \mathrm{~K}$. Thus, a system that is based on the Brazilian standard was implemented, but using a higher bandwidth channel $(6+6 \mathrm{MHz})$, Channel Bonding (CB) technique, soft decision demapper, Low-Density Parity-Check (LDPC) code and higher order modulations (256-QAM). In addition, some adjustments had to be made at some stages of the transmission and reception process, such as the development of an LDPC encoder and decoder and an uniform mapper and a soft decision demodulator, to be compatible with the modified system. The steps of interleaving (time and frequency), framing, Orthogonal Frequency Division Multiplexing (OFDM) modulation and Guard Interval (GI) insertion of the traditional ISDB-T $_{B}$ were used [17].

The proposed broadcast system was implemented in Software Defined Radio (SDR) by using GNU Radio Companion (GRC) software. The GRC is a free and open-source software development toolkit that provides signal processing blocks to achieve SDR. It can be used with readily-available low-cost external Radio Frequency (RF) hardware or without hardware in a simulation-like environment. The software allows the creation of blocks using programming languages such as $\mathrm{C}$, $\mathrm{C}++$ and Python [18].

This paper is organized into three sections. In Section II, the most relevant information about the implementation of the proposed system are presented. And finally, Section III, contains the conclusion of this work.

\section{8K-DTV BROADCAST SYSTEM IMPLEMENTATION}

\section{A. Transmitter}

At the transmission stage, a modified version of ISDB-T $\mathrm{T}_{B}$ was implemented using some characteristics of ATSC 3.0, but with a modified message size to guarantee synchronism. The proposed transmitter uses a tailored irregular LDPC code, with a frame size of $19968(4 \times 4992)$ instead of the traditional sizes used in ATSC 3.0 standard (Short frame: 16200 and Normal frame: 64800) [8]. After that, a mapper is implemented with a uniform 256-QAM constellation.

The Fig. 1 shows the custom irregular LDPC code of the frame size 19968 and code rate 13/15.

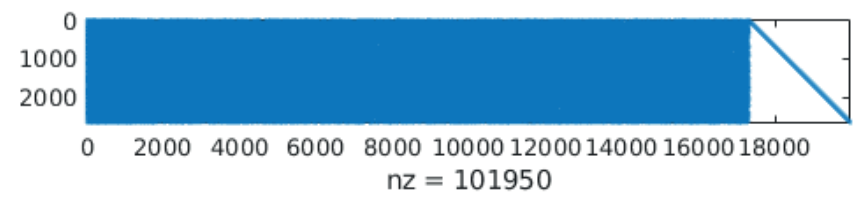

Fig. 1. Custom irregular LDPC code of the frame size 19968 and code rate $13 / 15$.

Fig. 2 shows one of the transmitted 256-QAM constellation using 13 segments (Layer 1 - Left side Radio Frequency (RF) channel). Another 256-QAM constellation is transmitted in the right adjacent RF channel (Layer 2). For both 8K-DTV signals, Mode $3(8 \mathrm{~K})$ was used and the Time Interleaver (TI) was set to 0 .

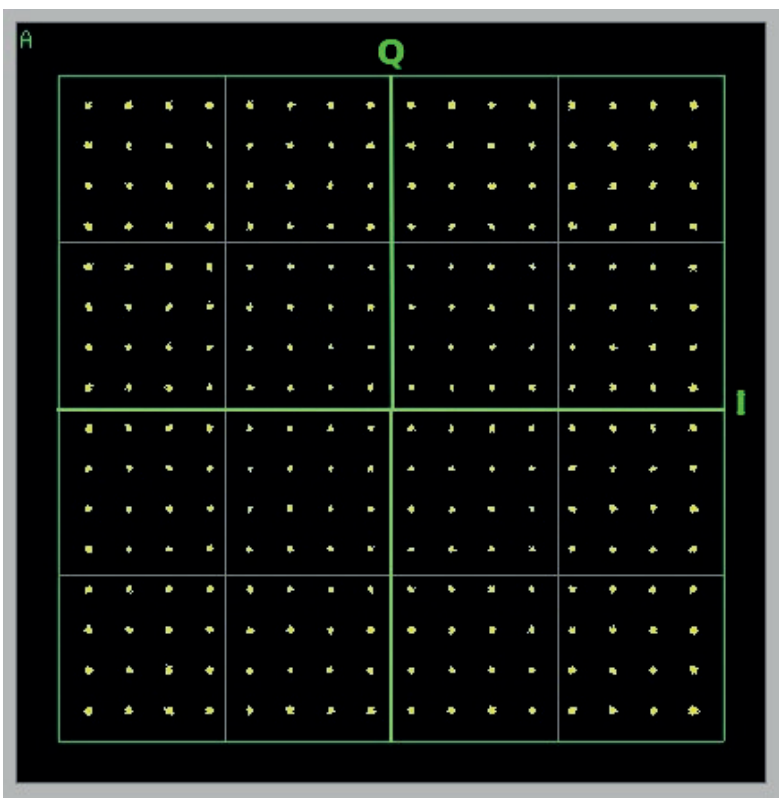

Fig. 2. 8K-DTV 256-QAM constellation (displayed on the spectrum analyzer).

To transmit a signal with a total bandwidth of $12 \mathrm{MHz}$, the proposed system used the Channel Bonding (CB) technique (an overall $12 \mathrm{MHz}$ signal is realized by two neighbored 6 MHz RF channels). This technology allows scalable expansion of effective bandwidth provided to the receiver through simultaneous deployment of radio resources across multiple carriers. With multiple RF channel bonding, the total bandwidth can be any sum of the default single RF channel bandwidths $(6 \mathrm{MHz}$ for $\operatorname{ISDB}_{-} \mathrm{T}_{B}$ ). [19].

The 8K-DTV spectrum using two channels with bandwidth of $6 \mathrm{MHz}$ is shown in Fig. 3.

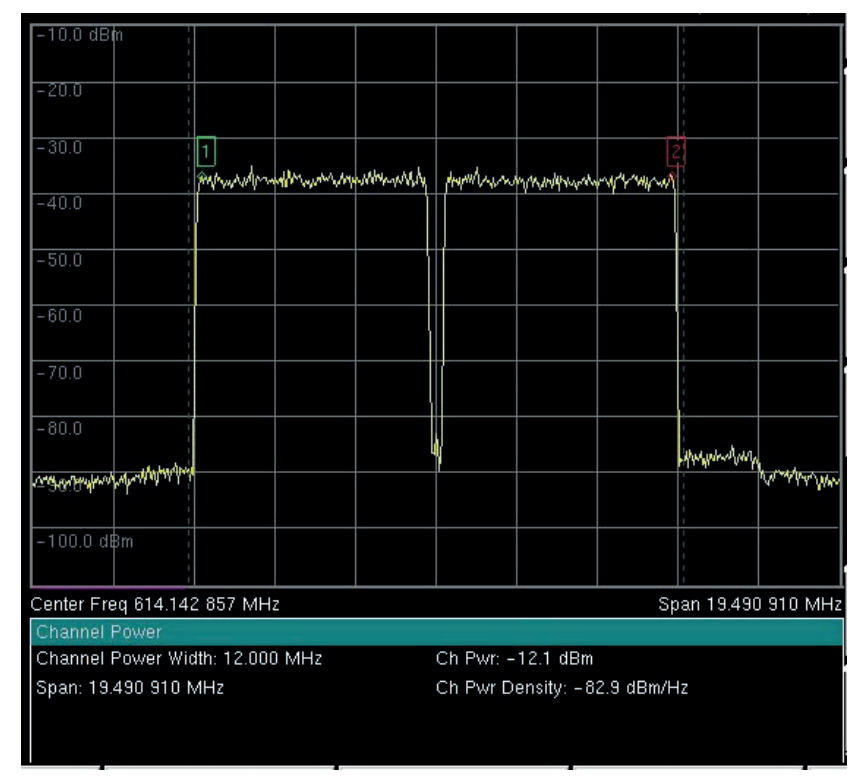

Fig. 3. 8K-DTV spectrum $(6+6 \mathrm{MHz})$.

The 8K-DTV transmitter using two channels with each having a bandwidth of $6 \mathrm{MHz}$ is shown in Fig. 4. 


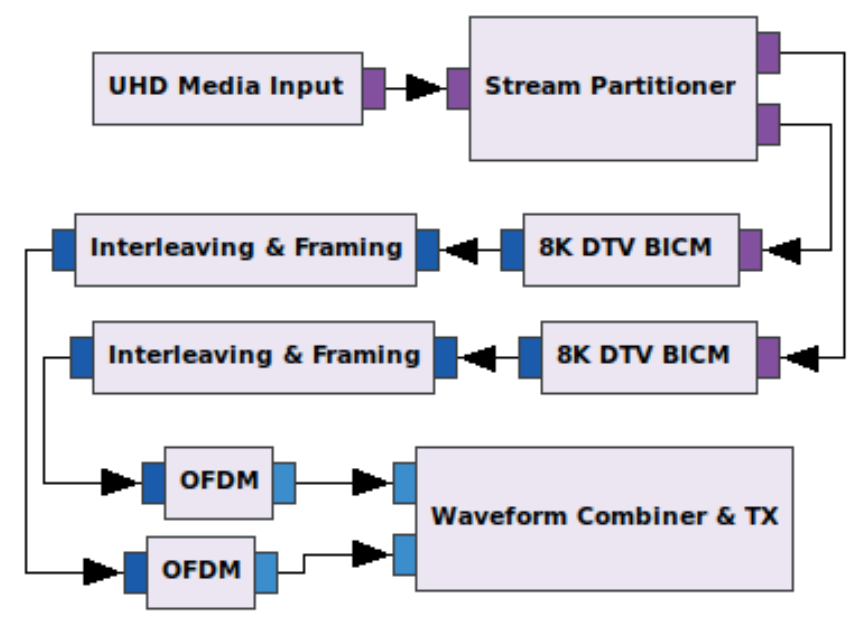

Fig. 4. 8K-DTV Transmitter using Channel Bonding.

In the diagram shown in the Fig. 4 the signal is separated in two streams before encoding and mapping stages. Both encoded and mapped streams are interleaved in time and frequency and passed through the stages of Framing, OFDM modulation and GI insertion separately [20]. After that, the modulated streams are transmitted on different Radio Frequency (RF) channels or spectrum parts from the TV transmitter [19].

For the correct functionality of this technique, it is necessary that the branches are synchronized similarly to the Single Frequency Networks (SFNs). In a SFN, a set of transmitters is synchronized in time and frequency to transmit the same signal. This means that all the transmitters of the network should transmit the same OFDM symbol at the same time and frequency [21]. Similarly, using CB technology, it is necessary for the transmitter branches to be synchronized, so that signals are transmitted at the same time [19].

One of the advantages of using the $\mathrm{CB}$ technique is that it is possible to transmit one $4 \mathrm{~K}$ resolution channel and a second channel used as a complement (complementary bits) to reach the $8 \mathrm{~K}$ resolution. In this work, one $8 \mathrm{~K}$ stream is separated in two streams in order to be transmitted and then these streams are added together (at the reception stage) to recover the original $8 \mathrm{~K}$ resolution Transport Stream (TS) file.

\section{B. Receiver}

The proposed receiver has $12 \mathrm{MHz}$ bandwidth to receive two adjacent channels. After that, the synchronization of time, sampling, frequency and frame is performed. Then, the steps of OFDM demodulation, channel estimation and equalization and time and frequency de-interleaving are performed. Finally, the implementation of the reception stage is done using a Soft Decision demodulator that uses Log-Likelihood Ratio (LLR), which statistically defines whether a bit is " 0 " or " 1 " and the Sum-Product Algorithm LDPC decoder (SPA) is selected due to its high error correction performance.

The 8K-DTV receiver using two adjacent channels with bandwidth of $6 \mathrm{MHz}$ is shown in Fig. 5 [15], [22].

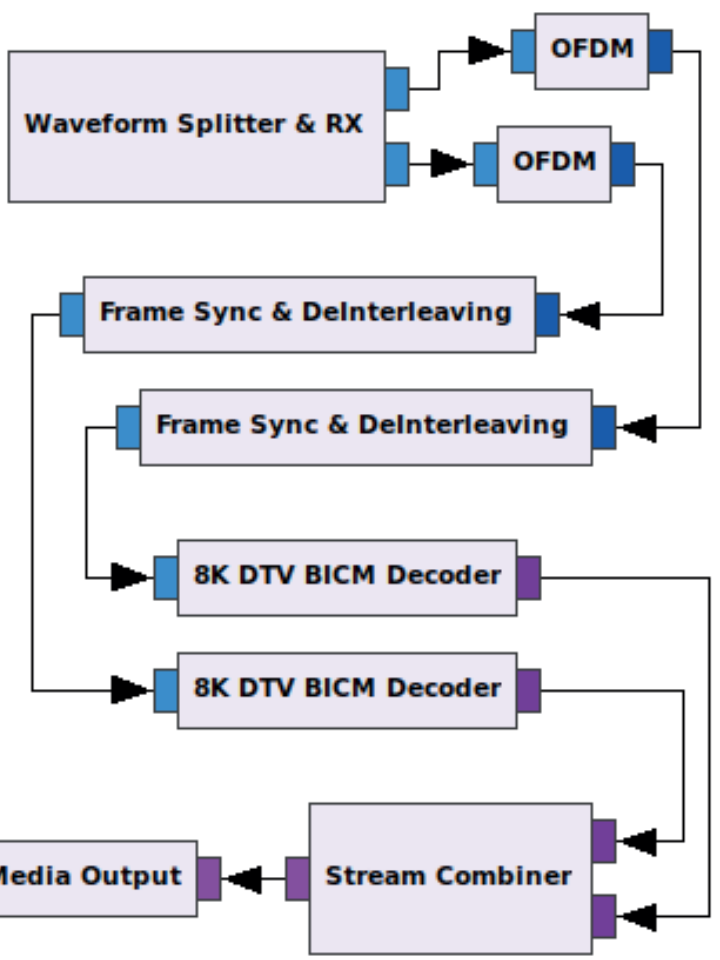

Fig. 5. 8K-DTV Receiver using Channel Bonding [15], [22].

In the diagram shown in the Fig. 5 [15], [22] the two signals are received (using multiple tuners that receive the modulated streams) and sent to the synchronization of time, sampling, frequency and frame stage. After that, the OFDM demodulation, channel estimation and equalization and time and frequency de-interleaving are performed. Both signals go through their respective demodulation and decoding steps (separately). Finally, they are combined in an unique stream [19].

\section{Simulation with LDPC Sum-Product Algorithm}

In order to verify the robustness of the 8K-DTV broadcast system, some simulations were done using the transmitter and receiver with $\mathrm{CB}$. The simulation with the optimal LDPC decoder SPA was done to confirm that the system can be improved in the future, using better techniques and configurations [23].

A computer simulation was performed in order to find the minimum Signal to Noise ratio (SNR) for the proposed system. During the simulation, the values of Bit Error Rate (BER) and Frame Error Rate (FER) were measured.

During the tests, an additive white Gaussian noise (AWGN) was injected in order to measure the SNR $(\mathrm{dB})$ value that corresponds to the BER threshold value of $3 \times 10^{-6}$ and FER of $1 \times 10^{-4}$ after applying the LDPC decoder. These thresholds are used considering a reception with less than one uncorrected error event per hour. This reception quality limit is defined as Quasi Error Free (QEF) and these values guarantee the QEF after the decoder [24]. 
The binary data source Pseudo-Random Binary Sequence 23 (PRBS 23) was used in all of the tests. The maximum number of iterations for the LDPC decoder was set to 40 .

For the first simulation configuration, a 16-QAM constellation, a Code Rate (CR) of 10/15 and 13/15, a frame size of 19968, a GI of $1 / 32$ and an Inverse Fast Fourier Transform (IFFT) size of $8 \mathrm{~K}$ were used. This configuration (with $\mathrm{CR}$ $=13 / 15$ ) allows the transmission of content in $4 \mathrm{~K}$ resolution. The second configuration used a 256-QAM with the same CR, frame size, GI and IFFT size, to achieve the $8 \mathrm{~K}$ resolution. The results are presented in Table I.

TABLE I

SNR THRESHOLDS WITH CB TECHNIQUE.

\begin{tabular}{|c|c|c|c|}
\hline $\begin{array}{c}\text { LDPC SPA } \\
\text { Simulation }\end{array}$ & $\begin{array}{c}\text { Bit rate } \\
\text { (Mbps) }\end{array}$ & $\begin{array}{c}\text { Video } \\
\text { Quality }\end{array}$ & $\begin{array}{c}\text { SNR threshold } \\
\text { (dB) }\end{array}$ \\
\hline $\begin{array}{c}\text { 16-QAM } \\
\text { CR = 10/15 }\end{array}$ & 27.58 & $4 \mathrm{~K}$ & 9.0 \\
\hline $\begin{array}{c}\text { 16-QAM } \\
\text { CR = 13/15 }\end{array}$ & 35.86 & $4 \mathrm{~K}$ & 13.0 \\
\hline $\begin{array}{c}\mathbf{2 5 6 - Q A M} \\
\text { CR = 10/15 }\end{array}$ & 55.16 & $4 \mathrm{~K}$ & 19.0 \\
\hline $\begin{array}{c}\mathbf{2 5 6 - Q A M} \\
\text { CR = 13/15 }\end{array}$ & 71.71 & $8 \mathrm{~K}$ & 24.0 \\
\hline
\end{tabular}

In the results shown in Table I the video quality information for all configurations were selected considering the use of High Efficiency Video Coding (HEVC).

\section{CONCLUSION}

The main objective of this work is reached, since the software transmission and reception with CB technology were achieved and a $8 \mathrm{~K}$ resolution content could be transmitted and recovered using higher order constellation, soft decision demodulation, using two adjacent channels of $6 \mathrm{MHz}$ and an optimal LDPC decoder (SPA).

The proposed 8K-DTV system was developed as a proof of concept, aiming to provide new ideas and possibilities for the development of a new digital TV standard for Brazil.

This work demonstrates the possibility of a software implementation of $8 \mathrm{~K}$ broadcast system. The system performance can be enhanced by adding other channel encoders such as the Bose-Chaudhuri-Hocquenghem $(\mathrm{BCH})$ and Cyclic Redundancy Check (CRC), for example. In addition, Non-Uniform Constellations (NUCs), bit and byte interleavers, more efficient ways to modulate and demodulate the signals, to realize the synchronization stages, among other techniques that could be used.

In addition to above factors, modern technologies applied to digital TV were also presented, such as the use of CB, which allows high bit rates to be achieved and permits the use of a channel with complementary information.

\section{ACKNOWLEDGMENT}

The authors would like to thank PPGEEC and their colleagues at Mackenzie's Digital TV Research Laboratory.

\section{REFERENCES}

[1] Digital Broadcasting Experts Group. (2018) Introduction of "ISDB-T", [Online]. Available: https://www.dibeg.org

[2] Resolution number 640, National Telecommunications Agency, July 2014, available in Portuguese. [Online]. Available: http://www.anatel. gov.br/legislacao/resolucoes/2014/785-resolucao-640\#art4

[3] MCTIC Regulation number 2992, of May 26, 2017, Ministry of Science, Technology, Innovation and Communications, 2017, available in Portuguese. [Online]. Available: https://www.mctic.gov.br/mctic/opencms/ legislacao/portarias/Portaria_MCTIC_n_2992_de_26052017.html

[4] M. Sugawara, "The world's first 8k/4k "regular" broadcasting," in Hollywood Professional Association 2017, feb. 2017.

[5] Parameter values for ultra-high definition television systems for production and international programme exchange, International Telecommunication Union - Radiocommunication Sector (ITU-R), 2015.

[6] T. Sakiyama, K. Ichikawa, M. Abe, S. Mitsuhashi, T. Yamashita, and M. Miyazaki, "8k-uhdtv production equipment and workflow which realize an unprecedented video experience," in SMPTE 2016 Annual Technical Conference and Exhibition, Oct 2016, pp. 1-11.

[7] S. Yamashita and K. Takahashi, "A 100gbps interface for 4k/8k uhdtv signals," in SMPTE 2016 Annual Technical Conference and Exhibition, Oct 2016, pp. 1-14.

[8] ATSC Standard: Physical Layer Protocol (A/322), Advanced Television Systems Committee, Washington, D.C, September 2016.

[9] S. Jeon, J. Lee, S. Kwon, B. Lim, S. Ahn, Y. Shin, J. Lee, and S. Park, "Field trial results for atsc 3.0 txid transmission and detection in single frequency network of seoul," in 2018 IEEE International Symposium on Broadband Multimedia Systems and Broadcasting (BMSB), June 2018, pp. 1-4.

[10] S. Park, J. Lee, S. Kwon, B. Lim, S. Ahn, H. M. Kim, S. Jeon, J. Lee, M. Simon, M. Aitken, K. Gage, Y. Wu, L. Zhang, W. Li, and J. Kim, "Performance analysis of all modulation and code combinations in atsc 3.0 physical layer protocol," IEEE Transactions on Broadcasting, vol. 65, no. 2, pp. 197-210, June 2019.

[11] NBR 15601: Digital terrestrial television - Transmission system, Brazilian Association of Technical Standards, Rio de Janeiro, 2008, available in Portuguese.

[12] Y. Sugito, S. Iwasaki, K. Chida, K. Iguchi, K. Kanda, X. Lei, H. Miyoshi, and K. Kazui, "A study on the required video bit-rate for 8k 120-hz hevc/h.265 temporal scalable coding," in 2018 Picture Coding Symposium (PCS), June 2018, pp. 106-110.

[13] G. H. M. G. de Oliveira, C. Akamine, and Y. P. Maciel, "Implementation of isdb-t ldm broadcast system using ldpc codes," in 2016 IEEE International Symposium on Broadband Multimedia Systems and Broadcasting (BMSB), June 2016, pp. 1-4.

[14] R. S. Rabaca, G. H. M. garcia de oliveira, G. R. Ganzaroli, F. Jerji, and C. Akamine, "Implementation of an isdb-tbldm broadcast system using the bicm stage of atsc 3.0 on enhanced layer and diversity at reception," in 2018 IEEE International Symposium on Broadband Multimedia Systems and Broadcasting (BMSB), June 2018, pp. 1-6.

[15] R. S. Rabaça, G. H. M. G. de Oliveira, F. Jerji, and C. Akamine, "Implementation of a real-time isdb-tb ldm receiver using sdr," in 2019 IEEE International Symposium on Broadband Multimedia Systems and Broadcasting (BMSB), June 2019, pp. 1-6.

[16] S. I. Park, H. M. Kim, and P. Angueira, "Hardware implementation and complexity analysis of layered division multiplexing (ldm) system for atsc 3.0," in NAB Broadcast Engineering Conference, 2015, pp. 77-81.

[17] Transmission System for Digital Terrestrial Broadcasting - STD-B31 V1.6 E2, Association of Radio Industries and Businesses, 2015.

[18] GNU Radio. (2018) GNU Radio Companion. [Online]. Available: https://wiki.gnuradio.org/index.php/Main_Page

[19] L. Stadelmeier, D. Schneider, J. Zöllner, and J. J. Gimenez, "Channel bonding for atsc3.0," IEEE Transactions on Broadcasting, vol. 62, no. 1, pp. 289-297, March 2016.

[20] R. S. Rabaça, C. Akamine, G. H. M. G. de Oliveira, and Y. P. Maciel, "Implementation of ldm/isdb-t broadcast system using diversity at reception," in 2017 IEEE International Symposium on Broadband Multimedia Systems and Broadcasting (BMSB), June 2017, pp. 1-4.

[21] C. Akamine, Y. Iano, G. de Melo Valeira, and G. Bedicks, "Remultiplexing isdb-t bts into dvb ts for sfn," IEEE Transactions on Broadcasting, vol. 55, no. 4, pp. 802-809, Dec 2009.

[22] F. Larroca, P. Flores-Guridi, G. Gómez, V. González Barbone, and P. Belzarena, "An open and free isdb-t full seg receiver implemented in gnu radio," in Wireless Innovation Forum Conference on Wireless Communications Technologies and Software Defined Radio (WInnComm 
16), Reston, Virginia, USA, 15-17 mar, 2016, pp. 1-10. [Online]. Available: https://iie.fing.edu.uy/publicaciones/2016/LFGGB16

[23] F. R. Kschischang, B. J. Frey, and H. Loeliger, "Factor graphs and the sum-product algorithm," IEEE Transactions on Information Theory, vol. 47, no. 2, pp. 498-519, Feb 2001.

[24] NorDig Unified Test Plan for Integrated Receiver Decoders for use in cable, satellite, terrestrial and IP-based networks, December 2017. [Online]. Available: https://nordig.org/wp-content/uploads/2017/ 12/NorDig-Unified_Test_Plan_ver_2.6.0.pdf 